\title{
Should Prices of Consumer Goods Be Better Indicators of Product Quality?
}

\author{
Heiner Imkamp ${ }^{1}$
}

Published online: 6 March 2018

(C) Springer Science+Business Media, LLC, part of Springer Nature 2018

\begin{abstract}
In contrast to the common assumption that prices are good indicators of quality, this note argues that price-quality correlations are typically rather low. Such low coefficients are not surprising since mass-produced goods of high quality may have lower prices than scarce goods of lower quality. In addition, low correlations can be characterized as desirable, since prices are an indicator not of quality but of scarcity.
\end{abstract}

"You always get what you pay for." This common saying suggests a close relationship between price and quality on consumer goods markets. When a product brand is superior in quality to its competitors, it is supposed to be also more expensive. Vice versa, a product having a higher price will, at the same time, also be a product of higher quality. Hence prices are expected to be good indicators of product quality.

This assumption, however, is not supported by empirical research. Many studies have shown that prices are not good indicators of quality. In the following, these studies will be summarized by three short statements. Remarkably, the authors of these numerous studies did not deal with the obvious normative question in the title of this paper. That gap will be filled below.

The first statement relates to the habit of consumers to use prices as quality indicators subjectively, irrespective of whether they are valid indicators in an objective sense at all. Consumers use prices as quality indicators, especially in situations, where other criteria of quality are lacking. In their eyes, a more expensive product is better than a cheaper one. This rating of quality by means of price has been studied and discussed quite often (e.g., Hofmann 2013; Völckner and Hofmann 2007), but it should be noted that this research on subjective habits of consumers should not be confused with the research on objective price-quality relations on markets, which is summarized succinctly in the following two statements.

The second statement reiterates the fact that, seen in an objective perspective, prices are indeed not good indicators of quality. In all studies, product quality was operationalized by

Heiner Imkamp

1 University of Hohenheim, Household and Consumer Economics (530A), Stuttgart, Germany 
comparative product test results. Correlating prices with test results provided, over the long haul of more than 65 years, constantly low correlations of about 0.2 on average.

When this correlation is transformed into a determination coefficient, the conclusion seems obvious: Only $4 \%$ of price variance among competing brands can be attributed to quality differences, whereas the remaining $96 \%$ have other causes, unrelated to product quality.

The reader should really savour this conclusion! It is supported by research spanning more than six decades. These far-flung studies have been reviewed rather often. For an early and very thoughtful review, see Geistfeld (1988), or for another very comprehensive one, Ratchford et al. (1996). In the years that followed they were summarized briefly by many other authors, mainly in English and German. This author, too, contributed short reviews in both languages; see Imkamp (2008) (English), and (2009) (German).

Looking back, one becomes aware that the whole line of research has, indeed, two starting points. It all began with Oxenfeldt (1950) who published the very first study using the methodological approach of correlating prices with comparative test results. The same approach was re-invented 27 years later by the German author Diller (1977) who, at that time, obviously was not aware of the earlier American studies. Maybe this was due to language barriers. As the Diller study was published only in German, it was ignored in the English literature for a long time. This is a pity, since it is one of the most sophisticated studies in the long line of price-quality research. It was based on a large sample of more than 4.000 product brands. Needless to say, it also revealed an average correlation of about 0.2.

The early studies have been succeeded by many others over the decades, even up to the recent past, (e.g., Kirchler et al. 2010; Roeben and Möser 2011). As a whole, the studies yielded remarkably uniform results. The low correlations were replicated not only in North America, but also in many European countries and in Asia.

The third statement focuses on the reactions of the authors to the numerous studies when putting their own results into perspective. Some authors seemed somewhat surprised by the low correlations they had found, others were disappointed, also by the fact that the coefficients did not even increase gradually over time, although markets were influenced by comparative product tests in many countries. Some authors diagnosed informational market failure, some deplored a lack of efficiency of markets, others saw informational imperfection of markets; "chaos of competition" was a frequently used interpretation. All these negative reactions (e.g., Diller 1977; Geistfeld 1988; Maynes 1979; Morris and Bronson 1969) to low price-quality correlations were highlighted several times, e.g., by Imkamp (2009).

Completely missing in the range of authors' reactions to their own findings is a certain "welcoming" to their results, or at least a sign of satisfaction with the low price-quality correlations. There are a few attempts to explain the low coefficients, mainly by methodological shortcomings. These attempts resulted, mostly, in the conjecture that the "true" correlations might be somewhat higher than the coefficients found empirically. Nowhere, however, are the low correlations viewed as economically meaningful, nor are there any attempts to find a rationale as to why low correlations might be even desirable. Instead, the general opinion seems to be: If consumer goods markets were fully functioning, the correlations ought to be higher.

This brings us back to the opening question of this short paper. I would like to repeat it here with a somewhat sceptical emphasis: Should prices of consumer goods really be better indicators of product quality than they have proved to be so far?

My answer to this question is an unequivocal "no." I state two arguments for this, a short one and a longer one. 
The shorter argument: One should remember that a product's grade of quality cannot be the main, single factor when setting prices. One must take several additional factors into account. Product quality may indeed be a major factor in this process, as higher quality may tend to increase the costs of production - but there are also opposing effects of higher quality, which may be able to reduce prices.

Such a price-reducing effect of higher quality can be illustrated by the following example. If consumers react sensitively to quality variations, then higher quality products will be more saleable and can thus not only be marketed in greater numbers but also be produced in greater quantities. This leads to economies of scale which, given enough competitive constraints, can lead to lower prices. Lower prices as a consequence of higher quality are possible - economies of scale are able to reduce the price-quality correlation (Imkamp 2008).

This line of reasoning lets us view low correlations in a fresh light. They can now be seen as indicators of flexible and sensitive demand and of sufficient workability of markets and competition. Low coefficients can be justified as economically meaningful and positive. For purely economic reasons, they do not need to be higher.

The second argument leads to the normative core of the question in the title of this paper. If not for economic reasons, would higher price-quality correlations perhaps be desirable for other reasons? My reasoning provides two answers to that question, but as they contradict each other, I will have to decide between them.

In the first instance, high coefficients would indeed be attractive, since consumers could use product prices as a convenient indicator of product quality. The price tag would be a valid product identification. Price comparisons would also be quality comparisons. Seen from the point of view of higher market transparency, high correlations should be welcomed (although it would be a pity that products of high quality would not be available at low prices, but would always be expensive).

In the second instance, high coefficients would not be desirable. Explaining the reasons for this answer requires a short look back at the economic history of dogma. The popular idea that prices should reflect the goods' grades of quality, turns out, on closer inspection, to be a re-edition of older ideas of the objective value doctrine. This doctrine explains price formation by attributing prices (as "exchange values") to the value of either the substance that is integrated into a product or, in the form of the labour value doctrine, of the amount of labour required to produce it.

From these older ideas the newer idea - that prices should be dependent on product quality - is not so far away. Replacing the terms "value of substance" and "amount of labour" by the term "degree of quality" demonstrates that the assumption of high price-quality correlations is in keeping with the tradition of the objective value doctrine. (Probably, most of the authors of the many correlation studies did not see this in the same way.)

Admittedly, the objective value doctrine is not really "false." It relates, however, primarily to the production side of goods and explains the costs of production. In this respect, it is doubtless of importance for the process of price formation. But the objective value doctrine has been complemented and relativized considerably by the subjective value doctrine with its strong focus on the demand side of price formation.

The main relevance of the subjective value doctrine for the present context rests upon the (re-assessed) emphasis on the explanatory power of the relative scarcity of goods, which depends on the relation between demand and supply of goods on the market. According to this conception, prices primarily do not signal quality, but are an indicator of scarcity. A consumer good has a higher price- if it is scarcer in supply than demand would require, not if it is merely superior in quality. Goods of high quality, which are offered abundantly, may definitely be cheaper than inferior products if the latter are hard to find. 
It is tempting to merge the concepts of the objective and the subjective value doctrine, and to claim that prices have a double function as indicators of quality as well as of scarcity. But that would have the undesirable consequence of a highly objectionable constellation of supply on markets: Product brands of high quality would not only be expensive, but they would also be scarce in supply while brands of poor quality would be cheap and readily available. As I have stated elsewhere (Imkamp 2008, p. 143): "the better the tested quality of a product brand is, the scarcer this brand is supplied on the market."

This disappointing configuration results from high price-quality correlations. Yet the opposite would be the more desirable, i.e., "High quality is abundant in the offer-poor quality may be scarce," which results from low or even negative coefficients.

So much for the second answer!

Choosing between the preceding two answers constitutes a dilemma. Does one give priority to the better information situation of consumers coming from high price-quality correlations, or does one's preference lie with the better supply situation resulting from low correlations, which imply that prices are not good quality indicators?

My decision is clearly in favour of the better supply situation and thus of low correlations. The reason is simple: The worse information situation for consumers, associated with low correlations, can more easily be overcome than poor supply. To compensate for insufficient information needs or informational shortcomings, there are efficient measures within the system of neutral consumer information policy. This system has comparative product testing at its core. A poor supply of consumers, on the other hand, could hardly be improved within a free-market economy system.

Seen together, the normative considerations support the low correlations which are usually found. That prices are not good quality indicators can be accepted if other valid quality indicators are available on the market.

The overall assessment of the evidence on the price-quality relationship reads as follows: The average coefficients are indeed rather small, but, after all, slightly positive. This shows that in the process of price formation, quality, apparently, is not completely lost: Price is, at least to some degree, an - albeit extremely weak - quality indicator. To this extent, also the fundamental ideas of the objective value doctrine are justified.

When, on the other hand, higher quality products can be marketed so successfully that they can be mass-produced, they can become cheaper. The effects of economies of scale make sure that the resulting correlations are not too high. Moreover, strong positive coefficients would be undesirable since they imply a poor supply of high quality goods. Low coefficients, in contrast, do not entail the risk of markets becoming flooded by goods of inferior quality.

To sum up, this short paper will hopefully contribute to bringing to an end the long discussion of low price-quality correlations on consumer goods markets. The persisting evidence is absolutely satisfying. My conclusion is that prices are not good indicators of product quality and that the state of affairs is as it should be.

\section{Compliance with Ethical Standards}

Conflict of Interest The author declares that he has no conflict of interest.

Ethical Approval The experimentation carried out through the study were carefully planned in accordance with the ethical standards set out by researcher's institutional ethics panel. In addition, the researchers adhered to ethical guidelines set out by The British Psychological Society's (BPS) Code of Human Research Ethics (2014). 
Informed Consent Written consent was a mandatory requirement for all participants. All participants were fully informed about the procedure and aims of the study, prior to giving consent. Due to the ethical considerations of exposing participants to violent footage, participants had to be informed that they would be viewing a CCTV footage that contained violence. All participants were psychologically capable of giving their own consent. Furthermore, participants were informed of their right to withdraw from the study at any time.

\section{References}

Diller, H. (1977). Der Preis als Qualitätsindikator. Die Betriebswirtschaft, 37, 219-234.

Geistfeld, L. V. (1988). The price quality relationship: The evidence we have, the evidence we need. In E. S. Maynes \& A. C. C. I. Research Committee (Eds.), The frontier of research in the consumer interest (pp. 143-172). Columbia: American Council on Consumer Interests.

Hofmann, T. (2013). Das Konzept der preisorientierten Qualitätsbeurteilung: Eine produkt- und kulturübergreifende kausalanalytische Betrachtung. Wiesbaden: Springer Gabler.

Imkamp, H. (2008). A new look at old coefficients. The price-quality relationship re-evaluated. Journal of Consumer Policy, 31, 139-145.

Imkamp, H. (2009). Welchen Zusammenhang zwischen Preis und Qualität sollte der Wettbewerb auf Konsumgütermärkten herstellen? Jahrbücher für Nationalökonomie und Statistik, 229, 410-425.

Kirchler, E., Fischer, F., \& Hölzl, E. (2010). Price and its relation to objective and subjective product quality: Evidence from the Austrian market. Journal of Consumer Policy, 33, 275-286.

Maynes, E. S. (1979). Consumer protection: The issues. Journal of Consumer Policy, 3, 97-109.

Morris, R. T., \& Bronson, C. S. (1969). The chaos of competition indicated by consumer reports. Journal of Marketing, 33, 26-34.

Oxenfeldt, A. R. (1950). Consumer knowledge: Its measurement and extent. Review of Economics and Statistics, $32,300-314$.

Ratchford, B. T., Agrawal, J., Grimm, P. E., \& Srinivasan, N. (1996). Toward understanding the measurement of market efficiency. Journal of Public Policy and Marketing, 15, 167-198.

Roeben, A., \& Möser, A. (2011). Was sagt der Preis über die Qualität von Lebensmitteln aus? Neue empirische Befunde am Beispiel von Fruchtsaft. Journal für Verbraucherschutz und Lebensmittelsicherheit, 6, 69-81.

Völckner, F., \& Hofmann, J. (2007). Price-perceived quality relationship. A meta-analytic review and assessment of its determinants. Marketing Letters, 18, 181-196.

The British Psychological Society. (2014). Code of Human Research Ethics. Retrieved from http://www.bps.org. uk/system/files/Public\%20files/code_of_human_research_ethics_dec_2014_inf180_web.pdf 